\title{
Learning in scaffolded autonomous e-learning environments amongst EAP students in a UK university
}

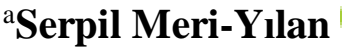 \\ a Assistant Prof. Dr., Ağrı İbrahim Çeçen University, Ağrı, Turkey, serpilmeri@ gmail.com
}

To cite this article: Meri-Yilan, S. (2019). Learning in scaffolded autonomous e-learning environments amongst EAP students in a UK university. Focus on ELT Journal (FELT), 1(1), 70-85. https://doi.org/10.14744/felt.2019.00002

\section{ABSTRACT}

As learners are working individually in e-learning environments, research has moved to focus on providing guidance for learners and helping them to take responsibility for their own learning. Therefore, this study aimed to shed light on both learner autonomy and scaffolding in e-learning environments. 35 international English as a Foreign Language (EFL) students who were taking a course supported with online learning resources (OLRs) including the English for Academic Purposes (EAP) Toolkit participated in the study voluntarily. Before taking the course, they filled a pre-questionnaire about their perceptions of learning, whilst a post-questionnaire at the end of the course. In the meantime, they were observed three times while carrying out activities in the Toolkit, and interviewed afterwards. Data from observations, interviews and questionnaires have shown that e-learning through scaffolding facilitates EFL learners' language learning and scaffolding has a significant impact on learner autonomy and vice versa. This study sets the grounds for learners to use scaffolding, teachers to implement scaffolding, institutions to provide a scaffolded autonomous e-learning environment and designers to set up that kind of environment in order to enable the educational equality and opportunity for all learners.
Keywords:

scaffolding

e-learning

learner autonomy

EFL learners

the EAP Toolkit

\section{Introduction}

The diversity in learners has caused institutions to implement advanced e-learning tools in order to enhance language learning. Bray, Brown and Green (2004) argue that cultural differences have a great impact on English language learning, especially in terms of learners' socioeconomic status, to use the technology. Mahinda (2014) furthers that both cultural and linguistic diversities can be detrimental in a shared language learning classroom. Without regard to these differences, all learners can benefit from the technology in the same way, for instance, to access an online material or play video games (ibid.), when they are provided with an e-learning tool in a virtual e-learning environment. Therefore, higher educational institutions have started offering virtual self-access centres (VSACs) that are institutional websites to facilitate 'independent language learning' (Gui \& Northern, 2013, p.1). VSACs are effective because it provides the following:

- 'resources for self-study' (ibid., p.1), 
- 'forums or message boards to encourage interaction' (ibid., p.1),

- 'affordances for autonomous learning' (Reinders \& White, 2011, p.1),

- an environment, where a learner can plan, improve and assess his or her learning (Lázaro \& Reinders, 2007),

- scaffolding for learners not to 'feel isolated and lost' (Shen, Cho, Tsai \& Marra, 2013, p. 10).

According to Universities UK (2018) report, there is a high demand of international students in coming to study in the UK. Having left their countries, students from different backgrounds, cultures and languages become minority in the country where the language is spoken. In this kind of a learning environment, educational institutions should prepare them for the diverse and advanced learning challenges ensuring 'equitable access to technology' (Chisholm, 1998, p.250). By this way, students can have the equal opportunity to reach the knowledge and information.

Kelly (1991) puts forward two views on education. One states that 'education is access to that which is worthwhile in a culture or an opportunity to develop one's intellect and extend one's scope' (ibid., p.30). This ensures educational access and opportunity to all students. The other view discusses that it cannot be available for everyone but for capable students, especially when it is in its initial stage as these students can make a profit. The present study does not regard the discrimination of the students coming from different backgrounds and cultures and embraces all students equally to see their process in language learning.

Considering the discussion about the social equality in education (Kelly, 1991) and technology access (Chishom, 1998) above, this paper deals with language learning of English as a foreign language (EFL) learners in a scaffolded e-learning environment. The aims of the study are to see what actions each student carried out in the EAP Toolkit and other OLRs, examine what students thought of the learning online, and look at their autonomous learning.

This paper covers the description of scaffolding in e-learning environments and its relationship with learner autonomy as well as the discussion of Laurillard's Conversational Framework. Netx, it introduces empirical findings from EFL learners' learning of OLRs. Ultimately, the findings from this study will help to conceptualize how e-learning environment can contribute to different newcomer students' language learning when provided with equal and accessible technology.

\section{Literature Review}

\section{Scaffolding in E-learning Environments}

E-learning environments is advantageous as it provides learners to collaborate, interact and learn synchronously or asynchronously, and teachers to adapt their teaching methods considering convenient accomplishment of the task (Mouzakitis, 2010; Pandey, 2013), different learning styles, 'timing, delivery, and accessibility' (Johnson, Hornik \& Salas, 2008 , p.357). However, they potentially impede learning since learners may be alone, feel isolated and encounter inappropriate contents with regard to their culture and inappropriate learning approaches (Pandey, 2013). This makes learners need supporting and guiding, especially when they work and handle their learning alone. Correspondingly, this has led to draw attention to scaffolding in e-learning environments. 
Scaffolding in the educational sense is referred to Vygotsky's zone of proximal development (ZPD), which is related to the distance between what learners can do independently and with guidance from teachers or peers (Vygotsky, 1978 cited in Lantolf $\&$ Thorne, 2006). With the advance of the technology and change of learning, scaffolding has evolved in e- learning environments (Puntambekar \& Hübscher, 2005). In this evolved sense, scaffolding can be permanent, whereas it fades in the original or traditional sense as learners become more capable of independent learning. Scaffolders can be provided by tools or resources in the former while teachers or peers provide scaffolding in the latter. Blanket scaffolding, which is the same for every student, and passive support, which does not spot mistakes apparently, can be offered, while the latter gives dynamic scaffolding with an ongoing diagnosis and adaptive scaffolding with a calibrated support. As there may be no human helper, a student forms a shared understanding with authentic tasks in the former, whilst teachers or peers do in the latter.

Researchers (i.e. Azevedo, Cromley, Thomas, Seibert \& Tron, 2003; Hannafin, Land \& Oliver, 1999; Tait, 2000; Yelland \& Masters, 2007) have also grouped scaffolding. Yelland and Masters (2007) categorise scaffolding into three types. Cognitive scaffolding is linked to 'those activities which pertain to the development of conceptual and procedural understandings which involve wither techniques or devices to assist the learner' (ibid., p.367). Technical scaffolding refers to using computers. Affective scaffolding refers to motivational help to further learning and increase learning abilities. Hannafin et al. (1999) give a deeper categorisation: Conceptual scaffolding helps 'what to consider' (ibid., p.132). Metacognitive scaffolding tells 'how to think during learning' (ibid., p.132). Procedural scaffolding shows the ways to implement resources. Strategic scaffolding guides to analyse, plan, make strategies and decide learning. These types have a possible impact on the learner motivation to use materials and tools (Tiantong \& Teemuangsai, 2013).

\section{Learner Autonomy and Scaffolded E-learning Environments}

Learner autonomy has been accepted as the ability to take responsibility for one's learning (Benson, 2011; Dickinson, 1987; Holec, 1981; Little, 1991). This paper draws on the relationship between learner autonomy and its dimensions such as learning strategies, selfmanagement, self-regulation and motivation in terms of attribution theory and self-efficacy (Benson, 2007). Therefore, this section first discusses these dimensions and then deals with learner autonomy in scaffolded e-learning environments.

Self-regulated learners can work independently by implementing, adjusting and preserving their learning ways in both collaborative and individual learning situations (Zimmerman, 2002). Similarly, self-managed learners can handle their learning by planning, monitoring and evaluating their learning processes (Lamb, 2010). Learning strategies regarded 'as the operations or processes which are consciously selected and employed by the learner to learn the TL [target language] or facilitate a language task' (White, 2008, p.9) can enable learners to accomplish the activities independently (Cohen, 2011). Oxford (2011) classifies learning strategies: Cognitive strategies are related to implementing learning by such as 'repetition, resourcing, translation, grouping, note taking, deduction, recombination, imagery, auditory representation, key word, contextualization, elaboration, transfer, inferencing' (Hismanoglu, 2000, n.p.). Metacognitive strategies refer to cognitive processes which is to plan' monitor, evaluate and manage learning, identify the problems 
and pay attention to the problem (O'Malley \& Cohen, 1990 cited in Benson, 2011). Social/affective strategies are the ways to contact with others such as collaborating with others or decreasing anxiety or supporting oneself for affective strategies (ibid.). These learning strategies can encourage learners to realise their learning (Allwright, 1990 cited in Oxford, 2003; Little, 1991). Besides, learners' attributions to success and failure (i.e. Attribution theory) and beliefs and confidence in their learning (i.e. self-efficacy) can affect them to handle the tasks on their own (Aliegro, 2006; Bandura, 1986; Banks \& Woolfson, 2008).

Although there has not been enough research on the relationship between the concepts of e-learning, scaffolding and learner autonomy (Jarvis, 2012; Yelland \& Masters, 2007), some studies have looked at them to some extent (Chen \& Law, 2016; Delen, Liew \& Willson, 2014; Nielsen, 2012). A study by Nielsen (2012) examined e-learning tools to foster learner autonomy in foreign language learning by conducting a case study to 24 international students. Data from the use of e-learning tools (i.e. individual plans, selfassessment, portfolio and online tests) showed that foreign language learning classrooms should include e-learning tools compulsorily for the student participation into learning. It also indicated the contrast use of tools between different backgrounds and genders. It concluded that the more they used the tools, the more autonomous and motivated they became.

Delen et al. (2014) explored the impacts of e-learning but in terms of the use of videos and made a comparison between scaffolded and unscaffolded online video learning platforms. Data from a Self-Regulation Strategy Inventory survey, a recall test and the frequency of students' use of the functions showed that the scaffolded online video learning platform with 'note-taking, supplemental resources, and practice questions' (ibid., p.314) increased participants' learning performance. The students in the scaffolded group outperformed others in the unscafffolded group. Delen et al. (2014) showed the scaffolding functions in e-learning environments. However, Chen and Law (2016) put stress on the comparison between collaboration and individual learning. The performance test and intrinsic motivation survey-indicated that 'scaffolding had an impact on students' motivation and learning performance' (ibid., p.1201) without regard to their individual or collaboration studies. Although these studies are crucial to see learner autonomy and scaffolding in elearning environments, they do not give a knowledge of these concepts together in elearning environments in terms of learning design. Therefore, Laurillard's Conversational framework has been discussed and used to implement scaffolding and in turn, promote learner autonomy in these environments.

\section{Laurillard's Conversational Framework}

Laurillard (2012) designed the Conversational Framework based on learning as conversation. This framework intends to promote the understanding of 'how to design teaching and learning now that digital technologies are making more impact on education' (ibid., pp. 94-5). According to the Conversational Framework, learning takes place via the interaction between the teacher and learner, or the learner and peer (ibid.). The framework was established on the research of Laurillard $(1998,2002)$ and highlights four essential components as follows:

- 'Discussion between teacher and learner at the level of descriptions; 
- 'Interaction between the learner and some special aspect of the world defined by the teacher;

- 'Adaptation of that special world by teacher, and of action by learner;

- 'Reflection on learner's performance by teacher and learner' (Laurillard, 1998, p.230).

Laurillard's Conversational Framework has been used by a number of researchers looking at the interaction between peers or peers and their teacher (see Fotouhi-Ghazvini, Earnshaw, Robison, Moeini \& Excell, 2011; Neo, Neo \& Lim, 2013; Quinn \& Reid, 2003). However, the present study is significant as it investigates the interaction learners and a tool when there is no any human helper in a learning environment. Therefore, this paper answers the following research questions:

1. What actions do EFL learners carry out in the EAP Toolkit and other OLRs?

2. What do EFL learners think of learning in scaffolded e-learning environments?

3. What is the relationship between scaffolding and learner autonomy in e-learning environments?

\section{Research Methodology \\ Participants}

Thirty-five international students aged between 20 and 45 years old volunteered to take part in the study. They came from the Middle Eastern (i.e. Iraq, Saudi Arabia, Jordan, Yemen and Libya) and Central Asian countries (i.e. China and Thailand). Despite these differences, they shared the same aim: They left their countries for the U.K. first to have and develop their academic skills and language learning and then to undertake undergraduate or postgraduate studies there. Their countries and institutions supported all of them except some Chinese students economically in order for them to study in the English for Academic Study (EAS) course at the University of Southampton and further their study if they could pass the course. During their course, they were supported to use the EAP Toolkit, so these participants were chosen.

The researcher contacted them in person. Before conducting the study, all of the participants were informed about the study and its aims. Each of them agreed and volunteered in the participation by signing the consent form. The anonymity was assured by excluding any question asking their name. The data were kept safe in passwordprotected devices and platforms.

\section{Context of the Research}

The EAS course aims to improve international students' academic language, for example, by increasing overall IELTS score of 4.5 or 5.5 to 6.5 or 7.0 to enter the university in the UK. Depending on their level of English, students take the course for either one semester (14 weeks) or two semesters (28 weeks). The participants in this study mostly took one semester although a few of them were mixed. They had a blended learning approach. During the course, they were encouraged to use online facilities suggested by teachers or decided on their own and in the University's language resources. They had a compulsory module named as Independent Study, where they were introduced the EAP Toolkit and other OLRs (online learning resources). Although the course was aimed at fostering independent learning and making them understand its place and importance in the British 
education system, they were free to choose this way and this potentially depended on the student's choice.

The EAP Toolkit was designed to potentially scaffold learning (Watson, 2010). Therefore, this Toolkit was chosen for the study. Based on the literature review and the researcher's analysis of the Toolkit, there were some scaffolders and scaffolding types found as explained below:

- The introduction section as a scaffolder first helps the user to have the basic idea about the learning topic.

- The explanation/information section as a scaffolder gives a detailed knowledge about what to grasp.

- The instruction section as a scaffolder tells how to perform and benefit from the activities.

- The feedback section provides explicit or implicit replies as a scaffolder.

- The self-scaffolder happens (Holton \& Clarke, 2006) when the user gives scaffolding to her or his learning on her or his own.

- Conceptual scaffolding is supplied when the Toolkit guides users to deal with problems by telling 'what to consider' (Hannafin et al., 1999, p.132).

- Metacognitive scaffolding gives an assistance on 'how to think during learning' (ibid., p.132).

- Procedural scaffolding gives the ways on how to carry out the activities (ibid.).

- Technical scaffolding is related to the guidance from e-learning tools (Yelland \& Masters, 2007). Web links, dictionary and glossary in the Toolkit can be examples of this scaffolding type.

As for the potential use of other OLRs, the participants were provided freely by accessing them in both the University laptops and at home. Apart from the advice by the University and teachers, there was a potential help from World Wide Web (Kirkwood, 2008).

\section{Data Collection Procedure and Analysis}

This study used a mixed methods approach to collect and analyse data. In order to increase the validity and reliability of the research and research instruments (Dörnyei, 2007), the study first conducted a pilot study to 12 students who took an EAS course at the University of Southampton during the summer term. As research instruments of the pilot study, a questionnaire and observation were trialed in the pilot study. Data from the pilot study showed that some questions needed adding and revising in the questionnaire, and a preand post-questionnaires were necessary, whereas observation needed to be recorded rather than directly observing. Considering the results from the data in the pilot study, the main study was conducted as follows:

As a quantitative research instrument, a questionnaire consisting of five sections (i.e. Background Information, Rating the EAP Toolkit and Online Language Learning Resources, Attribution Items, Self-efficacy Items and Learner Autonomy and Support Scale Items) was prepared based on the literature review. It was conducted to 35 students in the beginning and end of the academic semester with the aim of understanding students' beliefs about learning in a scaffolded e-learning environment. 
As for qualitative research instruments, direct observation with the think-aloud protocol method and the digital screen capturing with video, and follow-up interviews were implemented to 10 volunteers of 35 students in the beginning, middle and end of the academic semester. 'A pre-task orientation' (Gibson, 1997, p.58) was given to the students to be familiarised with the study (Van Someren, Barnard \& Sandberg, 1994). Each of them was told which activities in the EAP Toolkit to carry out in the first and second observation times but were free in the last one. The researcher directly observed by sitting behind each of them without intervening in them when they were doing the activities in the Toolkit for half of an hour. As resulted from the pilot study, noting their behaviours when they were performing the activities distracted them, so this was excluded. A silent room was prepared with a laptop to ensure them to feel comfortable like home. During the learning process, each of them was captured via Camtasia because of its easiness and efficiency (Lauffer, 2002; Silva, 2012). Camtasia recorded the full screen of the laptop, the webcam, elapsed time and the audio including the think-aloud protocol verbalisations. During observation sessions, the think-aloud protocol methods were applied in order to have an in-depth data about their learning (Blummer \& Kenton, 2014). The researcher told each of them to speak aloud what they were thinking and doing and stated that this study did not focus on whether they succeeded or failed but how they went through the information while doing the activities. After the observation, follow-up interview questions were asked to each student to understand their feelings, perceptions and use of OLRs.

As for data analysis, Statistical Package for the Social Sciences (SPSS) program helped to analyse quantitative data with descriptive statistics (i.e. frequencies and percentages of the variables) and inferential statistics (i.e. Spearman's rank-order correlation, McNemar's Test and Wilcoxon signed-rank test) to see the relationship between the variables and whether there was a statistical change in pre- and post-questionnaires.

Qualitative data was analysed within both deductive and inductive approaches based on pre-defined codes and codes generated from data through 'opening (unrestricted) coding' (Gale, Heath, Cameron, Rashid \& Redwood, 2013; p.3), respectively. The interviews and observations of each student were transcribed. In total, 29 interview transcripts and 29 observation transcripts including both think-aloud protocols and Camtasia recordings were collected from 10 students. As one of the students (Tase) could not attend the last interview and observation sessions, the number was 29 instead of 30 . She was included in the study because her data seemed valuable. Each transcript was stored in NVivo software and analysed with codes generated based on the literature review and research aims. Intercoder reliability (Campbell, Quincy, Osserman \& Pederson, 2013; Lombard, Snyder-Duch \& Bracken, 2010) was assured with the discussion and agreement on the codes with two experts and one supervisor.

\section{Results and Discussion}

\section{Learning Actions in Scaffolded E-learning Environments}

Data from qualitative and quantitative research instruments showed that there were different learning actions in a scaffolded e-learning environment. They differed in using scaffolding types, scaffolders, spending time in the activities and performing the activities.

Corroborating the analysis of the EAP Toolkit which provided different scaffolding types based on the studies (Azevedo et al., 2003; Hannafin et al., 1999; Tait, 2000; Yelland \& Masters, 2007), it was observed that the participants used procedural, metacognitive, 
strategic, conceptual, technical and motivational scaffolding. Participants used at least three scaffolding types in one observation time. The most used ones were metacognitive, procedural and conceptual scaffolding, which was dependent on not only what the Toolkit offered but also their preferences. It seemed that there was no motivational scaffolding but participants self-scaffolded themselves motivationally by thinking aloud. For example, they used the utterances such as 'Good! I did very well.' or 'Congratulation for myself!' independently from the Toolkit.

More than half of them improved their learning through strategic scaffolding. For example, they compared their understanding and reply with the one shown in the feedback and told the future behaviour to themselves. However, all of them used procedural scaffolding to understand how they could accomplish the tasks. Some showed their understanding by speaking aloud 'I understand it really.' In addition, they used conceptual and metacognitive scaffolding to further in the activities. For instance, they expressed their understanding of learning objects and corrected their misknowledge. The way they told themselves how to think, for instance, to select crucial words to grasp the topic shows metacognitive scaffolding. Even though one of them used technical scaffolding provided in the Toolkit, nearly half of them preferred to go beyond this help and used other OLRs such as Google and online dictionaries for further information. This shows that scaffolding types can help learning (Tiantong \& Teemuangsai, 2013). Although the Toolkit does not provide motivational scaffolding, the study argues that self-scaffolding can lead to motivational scaffolding. Additionally, learners can handle their learning on their own through scaffolding instead of teachers or peers (Hannafin et al., 1999; Luckin, 2001; Wood \& Wood, 1996).

Likewise, they differed in using scaffolders during the observations. All of them used at least three scaffolders. The most used were the information/explanation section, the instruction section and feedback. By this, they could have the further information about the activity and the ways to perform the activity and evaluate their learning (Puntambekar \& Hübscher, 2005). None of them used hyperlinks and dictionaries except one of them but other OLRs when they needed help. The use of feedback increased over time as seen with the comparison between the pre- and post-questionnaires. They also put stress on feedback as the most helpful scaffolder (Pea, 2004; Quintana, et al., 2004) in the interview sessions.

Also, all of them showed contrasting learning preferences in terms of spending time on the activities in the Toolkit based on their answers to the questionnaire. However, all of them spent less than 20 minutes during the observation sessions despite the differences and stated the same in the questionnaires contrasting with the study by Watson (2010), which claims that learners can spend between 20 and 40 minutes for one learning activity. This should be taken into account that they might be affected negatively when spending more time.

Learning differences happened in a scaffolded e-learning environment because of their learning preferences. Data from observations showed that they sometimes skipped the activity without completing it. Or they sometimes just read scaffolders without performing the activity or read them again and again to take the grasp of the information in the activity. Some behaved like that because they were affected with 'frustration, anxiety and confusion' (Zhang, Zhao, Zhou \& Nunamaker, 2004, p.76). This shows that the interaction between a learner and a tool depends on the learner himself or herself. However, it draws 
the attention to the design that is constructed with 'an integration of learning styles and preferences with strategies' (Sadler-Smith \& Smith, 2004, p.408).

Data from questionnaires showed that they performed more activities over time. McNemar's test indicated that there was a significantly statistical change in the EAP Toolkit use between questionnaires with .004 of p-value, but not in the use of other OLRs with .625 of $\mathrm{p}$-value. The Wilcoxon signed-rank test also showed the significantly statistical change in less time spent on the activities. They mostly preferred writing and vocabulary activities as shown in data from both questionnaires and observations.

All of them also uttered the use of other OLRs, most of which were EngVid, TED.com, the British Council resources including Word on the Street, apps on mobile phones, online journals and newspapers, e-books, Google and Google Scholar (Meri-Yilan, 2017).

Questionnaires indicated that the decrease of the daily use of other OLRs but the increase of the weekly use of OLRs over time. As stated by them, the decrease in use happened because of the homework load and hectic exam period in the classroom. However, participants mostly preferred to use scaffolding OLRs with subtitles, instruction and information. They pointed out the need and improvement of speaking activities. Therefore, a few of them uttered that they used discussion forums, social networking websites and communicating with native people such as 'a driver' in daily conversations.

\section{Learners' Beliefs about their Learning in Scaffolded E-learning Environments}

Data from open-ended questions in each questionnaire and interview questions show that participants had both positive and negative beliefs about learning in scaffolded e-learning environments. The data from both instruments indicated similar views, so they were not categorised based on data from either questionnaires or interviews. However, their views on learning via the EAP Toolkit and other OLRs differed, as shown in Figures 1 and 2 illustrated below respectively.

Figure 1 shows their positive and negative views according to three interview times. The figure also indicates that the participants expressed more positive views than negative ones about learning in the EAP Toolkit.

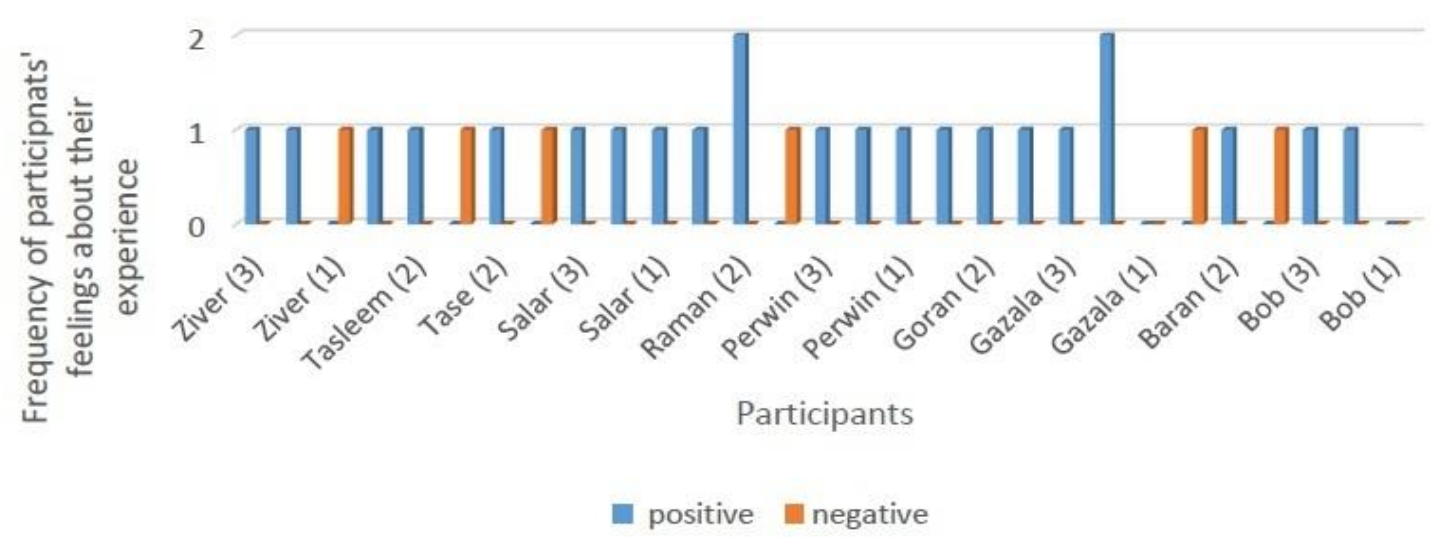

Figure 1. Participants' feelings about their experience of learning in the EAP Toolkit from interview data 
However, they seemed to have both positive and negative views on learning through other OLRs equally. Figure 2 illustrates their perceptions of other OLRs stated during all three interview times.

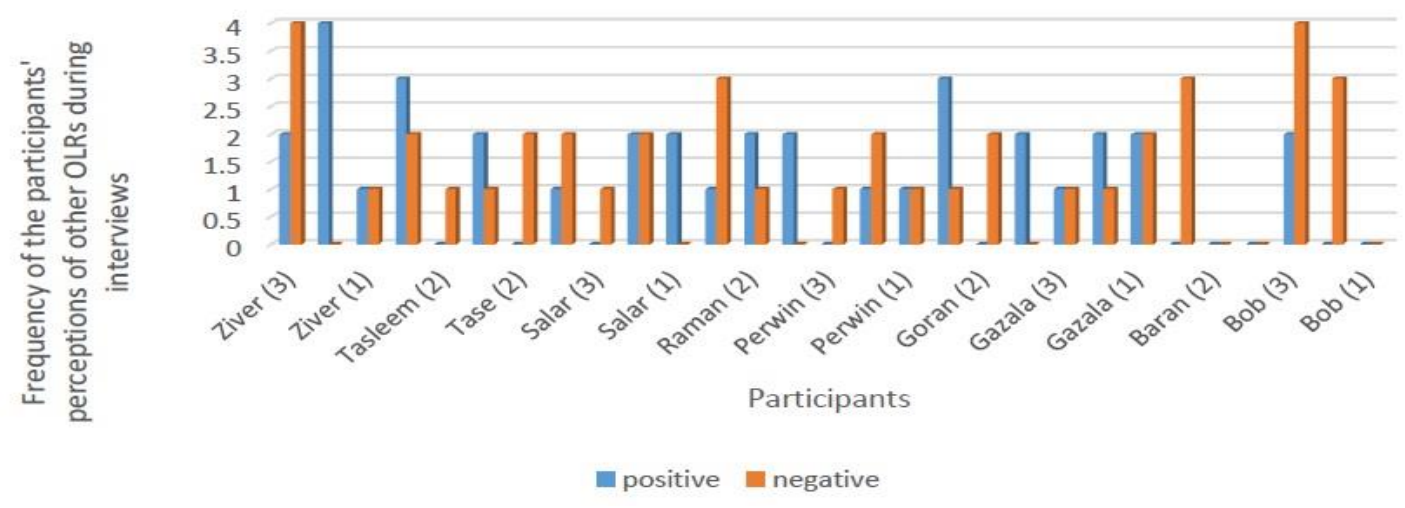

Figure 2. Participants' perceptions of other OLRs reported in Interviews

All in all, they believed that they increased their learning because of the following features of OLRs:

- the replacement and representation of the tutor (Hannafin et al., 1999; Luckin, 2001; Wood \& Wood, 1996);

- the interactivity;

- independent learning (Watson, 2010);

- learning skills except speaking skills;

- the provision of a variety of resources; and

- learning anytime and anywhere.

They thought that they could increase their learning if OLRs:

- provided more scaffolding and scaffolder but enough scaffolding and unclear scaffolder;

- enabled collaboration;

- included more resources which can be adaptable to different learners (Conole \& Dyke, 2004); and

- considered intercultural differences and academic skills.

The above mentioned suggestions can be seen as a criticism for OLRs to cover scaffolding, cooperation, engagement and diversity.

Indication of the Relationship between Learner Autonomy and Scaffolding in Elearning Environments

Based on the findings from both qualitative and quantitative data, this study discusses the relationship between scaffolding and learner autonomy in e-learning environments (Meri-Yilan, 2017). Data present that students exercised their autonomy with its related dimensions in e-learning environments. As shown in observations, they regulated and managed learning with the plan, goal making and assessment, evaluation, adjustment and implementation of learning independently. 
The findings from all instruments indicated their internal attributions towards their success and failure. Gobel, Thang, Sidhu, Oon \& Chan (2013) suggest that they are autonomous if students make internal attributions such as strategy, effort and ability. In this sense, they looked like to have learner autonomy. A Spearman's rank-order correlation showed a positive correlation between self-efficacy and attribution theory in the use of the Toolkit bot not in the use of other OLRs. Success, interaction and scaffolding seemed the preceding factors for confidence. Nevertheless, a Wilcoxon signed-rank test showed no difference between their feelings about online learning resources, their confidence in computer use, their daily computer uses and their use of computer and online applications between questionnaires.

Above all, they were observed that scaffolding from OLRs facilitated their learning, so participants:

- planned, paid attention, organised, obtained and used resources, monitored and evaluated their knowledge metacognitively,

- covered knowledge with their prediction and inference, conceptualised gradually with summarisation, gave a deductive and inductive reasoning and made a use of feelings for understanding cognitively,

- planned, paid attention, organised, obtained and used resources, monitored and evaluated feelings meta-affectively,

- activated encouraging feelings and perceptions affectively,

- planned, obtained and benefited from facilities for connection and cultural purposes metasociocultural-interactively,

- interacted to gain knowledge and connect sociocultural-interactively.

The analysis of pre- and post-questionnaire items in Learner Autonomy and Support Scale section finds out that scaffolding had an effect on learner autonomy. Referring to interviews, as well, participants needed a help from the tutor in e-learning environments due to the lack of scaffolding, particularly, which indicates the relationship between learner autonomy and scaffolding in e-learning environments. Based on the findings, Figure 3 shows the adapted model of Laurillard's (2012) Conversational Framework to consider this relationship. 


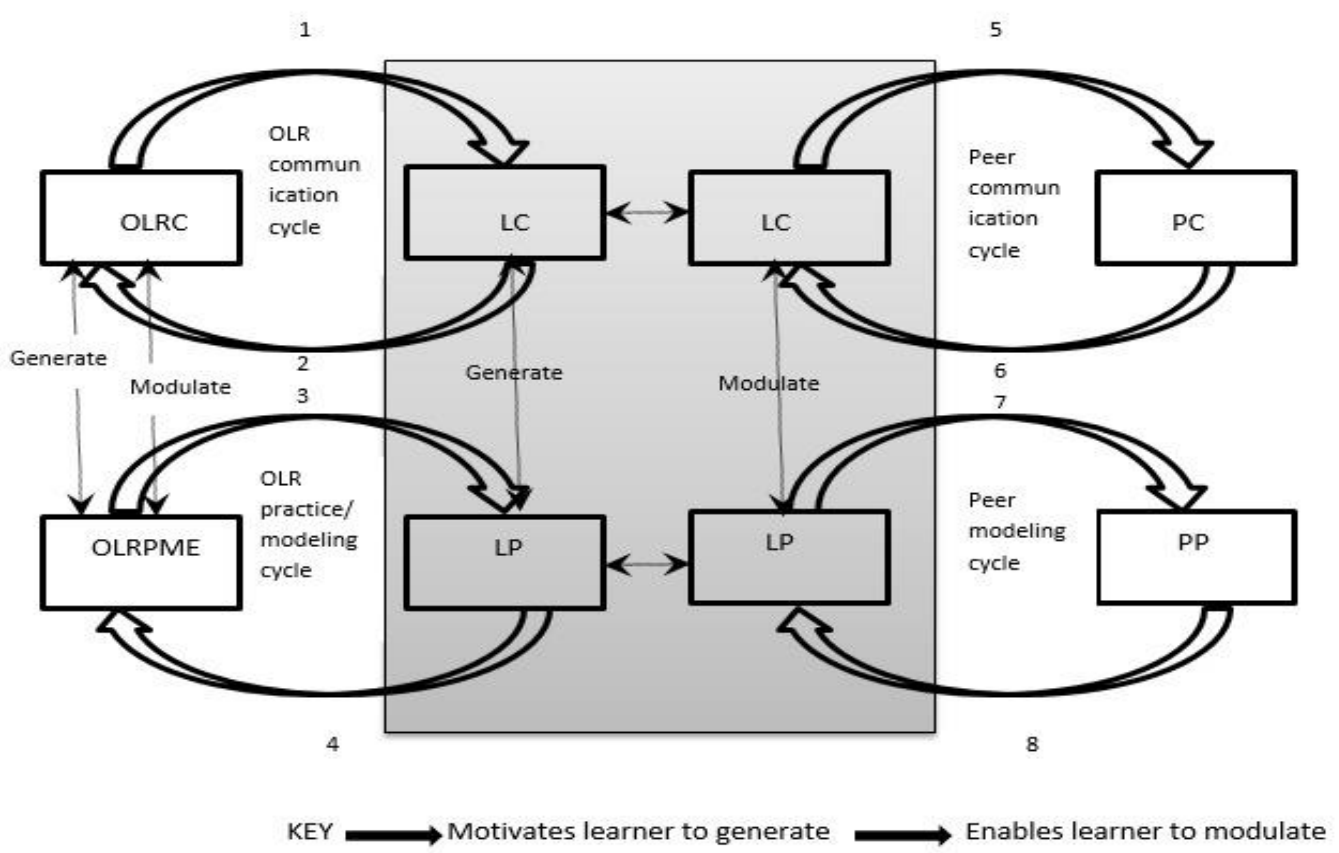

Figure 3. The adapted model of Laurillard's Conversational Framework (Meri-Yilan, 2017)

The exercise of learner autonomy without any help from a tutor or peers but scaffolding from OLRs discusses that learning can take place through adaptation of learning on one's own and interaction between a learner and OLRs as shown in Figure 3. In this sense, scaffolding can serve as a tutor (Luckin, 2001; Wood \& Wood, 1996). It can be inferred from the model that the more they interact with OLRs, the more they adapt themselves to learning and the more learning takes place.

\section{Conclusion}

This research has shed light on learner autonomy, scaffolding and their relationship in elearning environments where EFL learners aimed to improve their academic English without the help of any human. Scaffolding has a significant effect on learning accomplishment and enhancement, especially when learning alone without the support from any human beings. This also promotes learner autonomy, by which they can interact and adapt their learning with different learning strategies. This paper shows that what learners can do at the moment is facilitated through scaffolding types, scaffolders and selfscaffolding in order them to gain the understanding of what they can do independently in the future.

Therefore, this paper suggests for learners to consider the use of scaffolding in e-learning environments. The teachers should implement more scaffolding to decrease the tutor need in the classroom or online learning. The institutions should integrate more OLRs, particularly for their minority or international learners to enable the educational opportunity and equality. However, the designers have a big responsibility, as they are the ones who decide what to include and how to design. They should take into account the provision of different learning activities, learning skills and learning styles, appropriate colour of OLRs (Weinreich, Obendorf \& Lamersdorf, 2001), flexible learning, different scaffolding and scaffolders and implicit and explicit feedback. 
This study, however, focused on international EFL learners in the UK, but its findings and research instruments can be adapted in a further dataset and different context in order to see the relationship between scaffolding learner autonomy in e-learning environments where learners study individually and alone.

\section{Acknowledgements}

The researcher would like to acknowledge with gratitude to the Republic of Turkey for the financial support to conduct the research; the University of Southampton to allow to conduct it in its EAS course; and specially, Professor Vicky Wright for her support and feedback during the conduct and writing of the study.

\section{Disclosure Statement}

No potential conflict of interest was reported by the authors.

\section{References}

Aliegro, J. C. (2006). The effect of self-assessment on the self-efficacy of students studying Spanish as a foreign language. Unpublished PhD. Dissertation, University of Pittsburgh Graduate Faculty of School of Education, Pennsylvania.

Azevedo, R., Cromley, J. G., Thomas, L., Seibert, D., \& Tron, M. (2003). Online process scaffolding and students' self-regulated learning with hypermedia. Paper presented at the Annual Conference of the American Educational Research Association, Chicago, Illinois

Bandura, A. (1986). Social foundations of thought and action: A social cognitive theory. Englewood Cliffs, NJ: Prentice Hall.

Banks, M., \& Woolfson, L. (2008). Why do students think they fail? The relationship between attributions and academic self-perceptions. British Journal of Special Education, 35(1), 49-56. Doi: 10.1111/j.1467-8578.2008.00369.x.

Benson, P. (2007). Autonomy in language teaching and learning, Language Teaching. State of the Art Article. Language Teaching, 40, 1: 21-40. Doi: 10.1017/S0261444806003958.

Benson, P. (2011). Teaching and researching autonomy in language learning. (2nd edition) Harlow: Pearson.

Blummer, B., \& Kenton, J. M. (2014). Improving Student Information Search: A Metacognitive Approach. Oxford: Chandos Publishing.

Bray, M., Brown, A., \& Green, T. D. (2004). Technology and the Diverse Learner: A Guide to Classroom Practice. California: Corwin Press.

Campbell, J. L., Quincy, C., Osserman, J., \& Pedersen, O. K. (2013). Coding in-depth semistructured interviews problems of unitization and intercoder reliability and agreement. Sociological Methods \& Research. Doi: 10.1177/0049124113500475.

Chen, C. H., \& Law, V. (2016). Scaffolding individual and collaborative game-based learning in learning performance and intrinsic motivation. Computers in Human Behavior, 55, 1201-1212. Doi: 10.1016/j.chb.2015.03.010.

Chisholm, I. M. (1998). Six elements for technology integration in multicultural classrooms. Journal of Information Technology for Teacher Education, 7(2), 247-268. http://doi.org/10.1080/14759399800200033

Cohen, A. D. (2011). Strategies in learning and using a second language (2nd edition). London: Longman.

Conole, G., \& Dyke, M. (2004). What are the affordances of information and communication technologies? Association for Learning Technology Journal, 12(2), 113-124. Retrieved from http://core.ac.uk/download/pdf/14186.pdf.

Delen, E., Liew, J., \& Willson, V. (2014). Effects of interactivity and instructional scaffolding on learning: Self-regulation in online video-based environments. Computers \& Education, 78, 312-320. Doi:10.1016/j.compedu.2014.06.018.

Dickinson, L. (1987). Self-instruction in Language Learning. Cambridge: Cambridge University Press.

Dörnyei, Z. (2007). Research methods in applied linguistics. Oxford: Oxford University Press.

Fotouhi-Ghazvini, F., Earnshaw, R., Robison, D., Moeini, A., \& Excell, P. (2011). Using a conversational framework in mobile game based learning-assessment and evaluation. In International Conference on 
ICT in Teaching and Learning (pp. 200-213). Springer, Berlin, Heidelberg. Doi: 10.1007/978-3-64222383-9_17.

Gale, N. K., Heath, G., Cameron, E., Rashid, S., \& Redwood, S. (2013). Using the framework method for the analysis of qualitative data in multi-disciplinary health research. BMC Medical Research Methodology, 13(1), 117. Doi: 10.1186/1471-2288-13-117.

Gibson, B. (1997). Talking the Test: Using Verbal Report Data in Looking at the Processing of Cloze Tasks. Edinburgh Working Papers in Applied Linguistics, 8, 54-62. Retrieved from http://files.eric.ed.gov/fulltext/ED409713.pdf.

Gobel, P., Thang, S. M., Sidhu, G. K., Oon, S. I., \& Chan, Y. F. (2013). Attributions to Success and Failure in English Language Learning: A Comparative Study of Urban and Rural Undergraduates in Malaysia. Asian Social Science, 9(2), pp.53-62. Retrieved from http://ccsenet.org/journal/index.php/ass/article/view/24353/15408.

Gui, D.A.F. \& Northern, A. (2013). Supplementing self-access learning for an English Language Centre through virtual platforms. Presented at the Experiential Learning in Virtual Worlds 2013 Conference in Lisbon, Portugal.

Hannafin, M., Land, S., \& Oliver, K. (1999). Open learning environments: Foundations, methods, and models. In C. M. Reigeluth (Ed.), Instructional design theories and models, (Vol. 2, pp. 115-140). Mahway, NJ: Lawrence Erlbaum Associates, Inc.

Hismanoglu, M. (2000). Language learning strategies in foreign language learning and teaching. The Internet TESL Journal, 6(8), 12-12. Retrieved from http://iteslj.org/Articles/Hismanoglu-Strategies.html.

Holec, H. (1981). Autonomy in Foreign Language Learning. Oxford: Pergamon

Holton, D., \& Clarke, D. (2006). Scaffolding and metacognition. International Journal of Mathematical Education in Science and Technology, 37(2), 127-143. Doi: 10.1080/00207390500285818.

Jarvis, H. (2012). Computers and learner autonomy: trends and issues. British Council ELT, 387. Retrieved from http://englishagenda.britishcouncil.org/sites/ec/files/B208_ELTRP\%20Jarvis\%20Report_AW.pdf.

Johnson, R. D., Hornik, S., \& Salas, E. (2008). An empirical examination of factors contributing to the creation of successful e-learning environments. International Journal of Human-Computer Studies, 66(5), 356-369. Doi: 10.1016/j.ijhcs.2007.11.003.

Kelly, A.V. (1991). The National Curriculum: a Critical review. London: Paul Chapman Publishing Ltd.

Kirkwood, A. (2008). Getting it from the Web: Why and how online resources are used by independent undergraduate learners. Journal of Computer Assisted Learning, 24(5), 372-382. Doi: 10.1111/j.13652729.2007.00265.x.

Lamb, T.E. (2010) Assessment of autonomy or assessment for autonomy? Evaluating learner autonomy for formative purposes. In Paran, A. and Sercu, L. (Eds) Testing the untestable in language and education. Bristol, UK: Multilingual Matters/Channel View Publications 98-119.

Lantolf, J. P., \& Thorne, S. L. (2006). Sociocultural theory and second language learning. Retrieved from http://old.fltrp.com/download/07041802.pdf.

Lauffer, S. (2002). The Translation Process: an analysis of observational methodology. Cadernos de traduçao, 2(10), 59-74. Retrieved from https://periodicos.ufsc.br/index.php/traducao/article/view/6144/5702.

Laurillard, D. (1998). Multimedia and the learner's experience of narrative. Computers \& Education, 31(2), 229-242. Doi:10.1016/S0360-1315(98)00041-4.

Laurillard, D. (2002). Rethinking university teaching: A Conversational framework for the effective use of educational technology. London: Routledge/Falmer.

Laurillard, D. (2012). Teaching as a Design Science: Building Pedagogical Patterns for Learning and Technology. Oxon, UK: Routledge, Taylor \& Francis Group.

Lázaro, N., \& Reinders, H. (2007). Innovation in self-access: Three case studies. CALL-EJ Online, 8(2).

Little, D. (1991). Learner Autonomy. 1: Definitions, Issues and Problems. Dublin: Authentik.

Lombard, M., Snyder-Duch, J., \& Bracken, C. C. (2004). Practical resources for assessing and reporting intercoder reliability in content analysis research projects. Intercoder reliability. Retrieved from http://matthewlombard.com/reliability/.

Luckin, R. (2001). Designing children's software to ensure productive interactivity through collaboration in the zone of proximal development (ZPD). Information Technology in Childhood Education Annual, 13, 57-85. Retrieved from http://www.editlib.org/noaccess/8501/.

Mahinda, H. U. (2014). "Majority" and "Minority" Student Interaction in the ELT Class. Procedia - Social and Behavioral Sciences, 123, 35-43. http://doi.org/10.1016/j.sbspro.2014.01.1395 
Meri-Yilan, S. (2017). 'Take your time' to 'find yourself!': An exploration of scaffolded autonomous elearning environments amongst international students in a UK university (Doctoral dissertation, University of Southampton).

Mouzakitis, G. S. (2010). Social benefits of e-learning. In Conference proceedings of eLearning and Software for Education (eLSE) (No. 01, pp. 355-358). Retrieved from

Neo, M., Neo, K. T. K., \& Lim, S. T. L. (2013). Designing a Web-Based Multimedia Learning Environment with Laurillard's Conversational Framework: An Investigation on Instructional Relationships. Turkish Online Journal of Educational Technology-TOJET, 12(3), 39-50. Retrieved from https://files.eric.ed.gov/fulltext/EJ1016940.pdf.

Nielsen, H.L. (2012). E-learning and the Dilemma of Learner Autonomy: A Case Study of First Year University Students of Arabic, Orientalia Suecana, Vol. LXI, No. Suppl, 2012, pp. 89-106. Retrieved from http://www.diva-portal.org/smash/get/diva2:635258/FULLTEXT02.

Oxford, R. (2011). Teaching and Researching Language Learning Strategies. London: Routledge

Oxford, R. (2003). Language Learning Styles and Strategies: An Overview. Learning Styles \& Strategies/Oxford, GALA 2003. Retrieved from http://hyxy.nankai.edu.cn/jingpinke/buchongyuedu/learning\%20strategies\%20by\%200xford.pdf.

Pandey, D. (2013). Social benefits of e-learning. KDK College Journal Jan. Retrieved from https://ssrn.com/abstract=2290626.

Pea, R. D. (2004). The social and technological dimensions of scaffolding and related theoretical concepts for learning, education, and human activity. The Journal of the Learning Sciences, 13(3), 423-451. Retrieved from http://www.jstor.org/stable/1466943.

Puntambekar, S., \& Hübscher, R. (2005). Tools for scaffolding students in a complex learning environment: What have we gained and what have we missed? Educational Psychologist, 40(1), 1-12. Retrieved from http://reforma.fen.uchile.cl/Papers/Tools\%20for\%20Scaffolding\%20Students\%20in\%20a\%20Complex \%20Learning\%20Environment\%20-\%20Puntambekar.pdf.

Quinn, D. \& Reid, I. (2003). Using innovative online quizzes to assist learning. Proceedings of AusWeb03 Conference, Sanctuary Cove. Retrieved from http://ausweb.scu.edu.au/aw03/papers/quinn/paper.html.

Quintana, C., Reiser, B. J., Davis, E. A., Krajcik, J., Fretz, E., Duncan, R. G., Kyza, E., Edelson, D. \& Soloway, E. (2004). A Scaffolding Design Framework for Software to Support Science Inquiry. Journal of the Learning Sciences, 13(3), 337-386. Doi: 10.1207/s15327809j1s1303_4.

Reinders, H., \& White, C. (2011). Special issue commentary: Learner autonomy and new learning environments. Language Learning and Technology, 15(3), 1-3.

Sadler-Smith, E., \& Smith, P. J. (2004). Strategies for accommodating individuals' styles and preferences in flexible learning programmes. British Journal of Educational Technology, 35(4), 395-412. Doi: 10.1111/j.0007-1013.2004.00399.x.

Shen, D., Cho, M., Tsai, C., \& Marra, R. (2013). Unpacking Online Learning Experiences: Online Learning Self-efficacy and Learning Satisfaction. Internet and Higher Education, 19, pp. 10-17. DOI: 10.1016/j.iheduc.2013.04.001.

Silva, M. L. (2012). Camtasia in the classroom: Student attitudes and preferences for video commentary or Microsoft Word comments during the revision process. Computers and Composition, 29(1), 1-22. Retrieved from http://ac.els-cdn.com/S8755461511000867/1-s2.0-S8755461511000867main.pdf?_tid=d276d40c-2c35-11e6-875a00000aacb35e\&acdnat=1465252215_3b14c12ed69618ca6a7df11c122db969.

Tait, A. (2000). Planning student support for open and distance learning. Open Learning, 15(3), 287 - 299. Doi: $10.1080 / 713688410$.

Tiantong, M. \& Teemuangsai, S. (2013). The Four Scaffolding Modules for Collaborative Problem-based Learning through the Computer Network on Moodle LMS for the Computer Programming Course. International Education Studies, 6(5), pp. 47-55.

Universities UK. (2018). International Students: Quarterly Data Briefing. Retrieved from https://www.universitiesuk.ac.uk/policy-and-analysis/reports/Pages/Quarterly-International-DataRelease-pdf.aspx

Van Someren, M. W., Barnard, Y. F., \& Sandberg, J. A. C. (1994). The think aloud method: A practical guide to modeling cognitive processes. London: Academic Press.

Watson, J. (2010). A case study: Developing Learning Objects with an explicit learning design. Electronic Journal of e-Learning, 8(1) 2009, (pp41-50). Retrieved from http://www.ejel.org/issue/download.html?idArticle=159. 
Weinreich, H., Obendorf, H., \& Lamersdorf, W. (2001). The look of the link-concepts for the user interface of extended hyperlinks. In Proceedings of the 12th ACM Conference on Hypertext and Hypermedia (pp. 19-28). ACM. Retrieved from https://vsis-www.informatik.unihamburg.de/getDoc.php/publications/87/lookoflink.pdf.

White, C. (2008). Language learning strategies in independent language learning: An overview. In S. Hurd \& T. Lewis, Language learning strategies in independent settings, 3-24. Bristol, UK: Multilingual Matters.

Wood, D., \& Wood, H. (1996). Vygotsky, tutoring and learning. Oxford Review of Education, 22(1), 5-16. Doi:10.1080/0305498960220101.

Yelland, N. \& Masters, J. (2007). Rethinking scaffolding in the information age. Computers \& Education, 48(3), 362-382. DOI: 10.1016/j.compedu.2005.01.010.

Zhang, D., Zhao, J. L., Zhou, L., \& Nunamaker Jr, J. F. (2004). Can e-learning replace classroom learning? Communications of the ACM, 47(5), 75-79. DOI: http://dx.doi.org/10.1145/986213.986216

Zimmerman, B. J. (2002). Becoming a self-regulated learner: An overview. Theory into Practice, 4l(2), 6470. DOI: $10.1207 / \mathrm{s} 15430421$ tip4102_2.

\section{Copyrights}

Copyright for this article is retained by the author(s), with first publication rights granted to the Journal.

This is an open-access article distributed under the terms and conditions of the Creative Commons Attribution license (CC BY-NC-ND) (http://creativecommons.org/licenses/by-nc-nd/4.0/). 